Journal of Case Reports 2019;9(1):1-3

\title{
Escherichia hermannii - An Unusual Pathogen Causing Urinary Tract Infection
}

\author{
Ramya Raghavan ${ }^{1}$, Jharna Mandal ${ }^{1}$, Channaveerappa Bammigatti ${ }^{2}$
}

Departments of ${ }^{1}$ Microbiology and ${ }^{2}$ Medicine, Jawaharlal Postgraduate Institute of Medical Education and Research (JIPMER), Puducherry, India.

\section{Corresponding Author:}

Dr Jharna Mandal

Email:drjharna@gmail.com

This is an Open Access article distributed under the terms of the Creative Commons Attribution License (creativecommons.org/ licenses/by/3.0).

Received Accepted Published
July 8, 2018

December 9, 2018

January 5, 2019

\begin{abstract}
Background: Escherichia hermannii is a distinct non-pathogenic species within the Escherichia genus. Case Report: The authors hereby report a case of acute pyelonephritis caused by Escherichia hermannii in a 49-year-old lady with diabetes mellitus. Conclusion: Awareness about the organism as a potential cause of pyelonephritis is important as it can be easily mistaken for Escherichia coli.
\end{abstract}

Keywords: Diabetes Mellitus, Escherichia coli, Intraabdominal Infections, Pyelonephritis, Urinary Tract Infections.

\section{Introduction}

Escherichia hermannii was identified as a distinct non-pathogenic species within the Escherichia genus in the year 1982 [1]. Since then it has been found to be an opportunistic pathogen causing infections especially in the immunocompromised hosts [1]. E. hermannii associated urinary tract infections have been rarely reported. In this report, we describe a 49 year old lady with $E$. hermannii associated pyelonephritis further strengthening the view that $E$. hermannii may be pathogenic in certain situations.

\section{Case Report}

A 49 year old lady presented with complaints of left loin pain, fever with chills and vomiting for 10 days duration. She had an underlying type 2 diabetes mellitus diagnosed 17 years back and was on insulin therapy since for two years. At presentation of the current episode she was not on any antibiotics.
A mid-stream clean catch sample was sent for culture. The urine wet mount revealed more than 25 pus cells per high power field without RBCs and epithelial cells. Microscopic examination of gram stained smears of the urine revealed gram-negative rods with pus cells. The urine was processed for culture by plating on to Cysteine Lactose Electrolyte deficient medium (CLED) agar and blood agar (Hi Media) and was incubated at $37^{\circ} \mathrm{C}$ for 24 hours and the next day the colonies were found to be non-lactose fermentors with a count of more than $10^{5}$ colonies. On day two, yellow pigment was appreciated in the Mueller Hinton Agar which was used for performing Antibiotic Susceptibility Testing. The following biochemical reactions were noted. It was catalase-positive, oxidase-negative, formed indole, citrate negative, urease negative, methyl red positive, ONPG-positive (O-nitrophenyl-beta-Dgalactopyranoside), reduced nitrates, produced acid from carbohydrates like glucose, sucrose, lactose, 
$\mathrm{H}_{2} \mathrm{~S}$-negative, fermented cellobiose, it did not decarboxylate lysine but decarboxylated ornithine. It grows in the presence of potassium cyanide (KCN) which was not tested due to its unavailability. The major distinction is by the production of yellow pigment amongst the Escherichia genus [1]. The antimicrobial susceptibility (AST) was carried out as per the Clinical Laboratory Standards Institute (CLSI) using the Kirby Bauer disc diffusion method for antibiotics namely, amikacin $(30 \mu \mathrm{g})$, gentamycin $(5 \mu \mathrm{g})$, ceftazidime $(30 \mu \mathrm{g})$, ceftriaxone $(30 \mu \mathrm{g})$, ciprofloxacin $(5 \mu \mathrm{g})$, meropenem $(10 \mu \mathrm{g})$ and nitrofurantoin (300 U) [2]. The organism was sensitive to amikacin $(24 \mathrm{~mm})$ and gentamicin (18 $\mathrm{mm})$ but resistant to the other antibiotics. The patient was treated with intravenous amikacin to which she responded well. The urine culture was repeated after a week which did not show any bacterial growth.

She had two hospitalizations in the past one year for treatment of urinary tract infection. On both occasions, significant bacterial counts of Escherichia coli were isolated in the urine culture. Both times the organism was sensitive to amikacin and gentamicin. With the recent episode the patient was admitted with the same symptoms.

\section{Discussion}

Acute pyelonephritis is the bacterial infection of the renal parenchyma. Bacteria usually reach the kidney by ascending from the lower urinary tract or may reach the kidney via the bloodstream. The most common organism responsible that is reported to cause pyelonephritis is Escherichia coli followed by Proteus spp, Klebsiella spp etc. [3]. Catheterization, congenital anomalies, immunosuppression therapy, post-transplant status, renal stones, diabetes mellitus are the major risk factors for UTI amongst which diabetes mellitus ranks highest in most of the studies.

Escherichia hermannii is a distinct species within the Escherichia genus. Not being aware of this organism may lead to an erroneous report of Escherichia coli. Routine biochemical tests namely, production of indole, citrate utilization and urea hydrolysis for identification of the organism would not suffice for its identification, thus it remains to be the organism of ignorance. Considering the pathogenicity of the organism it is essential to identify this organism based upon its specific biochemical reactions. On the retrospect, the earlier isolates could have been E. hermannii which may have been missed because of our ignorance.

Although considered non-pathogenic initially, it has been found to be associated with purulent conjunctivitis [4], neonatal sepsis [5], catheter associated blood stream infections [6], and pyelonephritis [7]. It was first described as a sole pathogen causing pyelonephritis by Yan Qing Tong et al. [8]. It confers resistance to beta-lactam antibiotics by the production of beta lactamase enzymes [9]. The risk factors stated for E. hermannii infections are immunocompromised state like diabetes mellitus, malignancy, extremes of age etc. The index patient was a diabetic and had a history of prior urinary tract infections. Presence of symptoms of pyelonephritis with significant pus cells in urine with only a single organism being isolated in the urine proves it beyond doubt that $E$. hermannii was the cause for the infection in the index patient. In a previous report, it was stated that the pyelonephritis caused by E. hermannii may be only mild and the organism may not be very virulent. Our report differs from this view, as the index patient had high grade fever, loin pain and associated vomiting, all of which suggest a severe infection.

The present observation further supports the view that E. hermannii may in fact be pathogenic and could cause invasive infections of varying severity. The uropathogenicity of this organism remains to be conclusively established and the treatment options must be standardized as these 
organisms are resistant to few antibiotics and also has the capability to form biofilms [10]. Further studies in this regard are the need of the hour.

\section{Conclusion}

E. hermannii is pathogenic and can cause invasive infections of varying severity.

Contributors: RR wrote the discussion and references, and did literature search. JM manuscript writing, helped in literature search and treatment protocol. CB managed the patient and provided critical inputs in manuscript writing. JM will act as guarantor of study. All authors approved the final version of this manuscript.

Funding: None; Competing interests: None stated.

\section{References}

1. Brenner DJ, Davis BR, Steigerwalt AG, Riddle CF, McWhorter AC, Allen SD, et al. Atypical biogroups of Escherichia coli found in clinical specimens and description of Escherichia hermannii sp. nov. J Clin Microbiol. 1982;15:703-713.

2. Park KH, Chong YP, Kim SH, Lee SO, Lee MS, Sung H, et al. Impact of revised broad-spectrum cephalosporin clinical and laboratory standards institute breakpoints on susceptibility in enterobacteriaceae producing AmpC $\beta$-Lactamase. Infect Chemother. 2017;49:62-67.

3. Buonaiuto VA, Marquez I, De Toro I, Joya C, RuizMesa JD, Seara R, et al. Clinical and epidemiological features and prognosis of complicated pyelonephritis: a prospective observational single hospital-based study. BMC Infect Dis [Internet]. 2014;14:639.

4. Poulou A, Dimitroulia E, Markou F, Tsakris A. Escherichia hermannii as the sole isolate from a patient with purulent conjunctivitis. J Clin Microbiol. 2008;46:3848-3849.

5. Ginsberg HG, Daum RS. Escherichia hermannii sepsis with duodenal perforation in a neonate. Pediatr Infect Dis J. 1987;6:300-302.

6. Rank CU, Lommer Kristensen P, Schrøder Hansen D, Brandi L. Catheter related Escherichia hermannii sepsis in a haemodialysis patient. Open Microbiol J. 2016;10:1-3.

7. Scholes D, Hooton TM, Roberts PL, Stapleton AE, Gupta K, Stamm WE. Risk factors for recurrent urinary tract infection in young women. J Infect Dis. 2000;182:11771182.

8. Tong YQ, Xin B, Sun SQ. Pyelonephritis caused solely by Escherichia hermanii. Jundishapur $\mathrm{J}$ Microbiol. 2014;7:e18138.

9. Fitoussi F, Arlet G, Grimont PA, Lagrange P, Philippon A. Escherichia hermannii: susceptibility pattern to betalactams and production of beta-lactamase. J Antimicrob Chemother. 1995;36:537-543.

10. Yamanaka T, Sumita-Sasazaki Y, Sugimori C, Matsumoto-Mashimo C, Yamane K, Mizukawa K, et al. Biofilm-like structures and pathogenicity of Escherichia hermannii YS-11, a clinical isolate from a persistent apical periodontitis lesion. FEMS Immunol Med Microbiol. 2010;59:456-465. 